Oral

\title{
KNOWLEDGE, ATTITUDE, AND PRACTICE OF SELF-WOUND MANAGEMENT AMONG PATIENTS WITH DIABETIC FOOT ULCER (DFU) IN PAHANG
}

\author{
Sanisah Saidi ${ }^{1}$ and Hamizah Farouzy ${ }^{1}$ \\ ${ }^{1}$ Kulliyyah of Nursing, IIUM,Kuantan, Pahang, Malaysia. \\ Presenter: Sanisah Saidi, sanisahsaidi@iium.edu.my
}

Introduction: A survey in 2011 reported that the prevalence of diabetes in Malaysia is $20.8 \%$ (2.8 million people) and $88 \%$ have uncontrolleddiabetes. Diabetic foot ulcer (DFU) is one of the common diabetes complications in Malaysia that leads to other devastated situation including infection, amputation and death. In Pahang, $95 \%$ of the patients have uncontrolled diabetes and $50 \%$ of them suffered from DFU. Self-wound management is an important element in reducing the risk of further complications of DFU. However, little is known on the patients' understanding of diabetes and their practice of selfwound management. This study aimed to understand the knowledge, attitude and practice of self-wound management among patients with diabetic ulcer in Pahang.

Materials and method: A quantitative, cross-sectional study was conducted in a tertiary hospital in Pahang involving 100 participants. Participants were recruited using purposive sampling from April 2017 until May 2017. Participants' knowledge, attitude and practice of self-wound management were measured using self-administered questionnaires. Additionally, the data on socio-demographic was gathered. The data was computed into SPSS and analyzed using descriptive and inferential statistics.

Results: Out of 100 participants, $95 \%$ of them had good knowledge on diabetes and DFU, $84 \%$ had a positive attitude towards self-wound management and $56 \%$ perceived good practices of self-wound management. However, a chi-square test between knowledge on diabetes and DFU and practice of self-wound management found no significant interaction $(p>0.05)$. Meanwhile, there was a significant interaction between attitude and practice of self-wound management $(p<0.05)$.

Conclusion: Good knowledge on diabetes and DFU do not determine the patients' practice of self-wound management. However, positive attitude towards self-wound management would contribute to the practice and willingness of the patients to selfmanage their foot ulcer wound at home. 